\title{
Review Article \\ Biology of Heme in Mammalian Erythroid Cells and Related Disorders
}

\author{
Tohru Fujiwara ${ }^{1,2}$ and Hideo Harigae ${ }^{1,2}$ \\ ${ }^{1}$ Department of Hematology and Rheumatology, Tohoku University Graduate School of Medicine, Sendai 980-8575, Japan \\ ${ }^{2}$ Molecular Hematology/Oncology, Tohoku University Graduate School of Medicine, Sendai 980-8575, Japan
}

Correspondence should be addressed to Tohru Fujiwara; fujiwara-to@apple.email.ne.jp

Received 11 April 2015; Accepted 14 June 2015

Academic Editor: Aurora M. Cianciarullo

Copyright (C) 2015 T. Fujiwara and H. Harigae. This is an open access article distributed under the Creative Commons Attribution License, which permits unrestricted use, distribution, and reproduction in any medium, provided the original work is properly cited.

\begin{abstract}
Heme is a prosthetic group comprising ferrous iron $\left(\mathrm{Fe}^{2+}\right)$ and protoporphyrin IX and is an essential cofactor in various biological processes such as oxygen transport (hemoglobin) and storage (myoglobin) and electron transfer (respiratory cytochromes) in addition to its role as a structural component of hemoproteins. Heme biosynthesis is induced during erythroid differentiation and is coordinated with the expression of genes involved in globin formation and iron acquisition/transport. However, erythroid and nonerythroid cells exhibit distinct differences in the heme biosynthetic pathway regulation. Defects of heme biosynthesis in developing erythroblasts can have profound medical implications, as represented by sideroblastic anemia. This review will focus on the biology of heme in mammalian erythroid cells, including the heme biosynthetic pathway as well as the regulatory role of heme and human disorders that arise from defective heme synthesis.
\end{abstract}

\section{Heme Biosynthesis}

The mammalian heme biosynthetic pathway includes eight enzymes (reviewed in [1-5]) (Figure 1). The first and ratelimiting step of this pathway is the condensation of glycine and succinyl-CoA to form 5-aminolevulinic acid (ALA), a 5-carbon aminoketone, in the mitochondrial matrix. This reaction is catalyzed by ALA synthase (ALAS). ALAS has two isozymes encoded by the housekeeping and erythroidspecific ALAS2 genes, which are termed ALAS1 (or ALAS$\mathrm{N}$ ) and ALAS2 (or ALAS-E), respectively. The human genes encoding ALAS1 and ALAS2 have been mapped on 3p21.1 [6] and Xp11.21 [7], respectively. Whereas heme negatively regulates ALAS1 expression by directly binding to a CP motif (described later) [1], ALAS2 expression is strongly induced during the later stage of erythroid differentiation. The regulatory region of the ALAS2 gene contains transcription factorbinding elements such as CCAAT, TATA, GATA, CACCC, Spl, and GATA-1 that are thought to induce erythroidspecific expression of the ALAS2 gene $[8,9]$. Furthermore, the $5^{\prime}$-untranslated region (UTR) of ALAS2 contains an ironresponsive element (IRE) that interacts with iron-responsive proteins (IRPs), thereby regulating ALAS2 expression at the posttranscriptional level. Under conditions of iron deficiency, ALAS2 translation is inhibited by the binding of IRPs to the IRE; in contrast, IRPs detach from the IRE under conditions of iron sufficiency, resulting in increased ALAS2 translation (for the IRP-IRE system, described later).

ALA is exported to the cytosol, where two molecules of ALA are condensed into the monopyrrole porphobilinogen (PBG), which is generated by PBG synthase (PBGS). The PBGS crystal structure is homo-octomeric, and each monomer binds one zinc atom to exert its enzymatic activity [10]. In addition, both housekeeping and erythroid-specific PBGS mRNAs have been detected. However, these mRNAs differ only in the $5^{\prime}$-UTR, and thus the housekeeping and erythroid-specific forms of the PBGS enzyme are identical [11].

Four PBG molecules are joined by hydroxymethylbilane synthase (HMBS) to form the first cyclic tetrapyrrole HMB, which is then converted to uroporphyrinogen III by uroporphyrinogen synthase (UROS). Uroporphyrinogen III is subsequently decarboxylated by uroporphyrinogen decarboxylase (UROD) to form coproporphyrinogen III. Similar to $P B G S$, both housekeeping and erythroid-specific mRNAs 


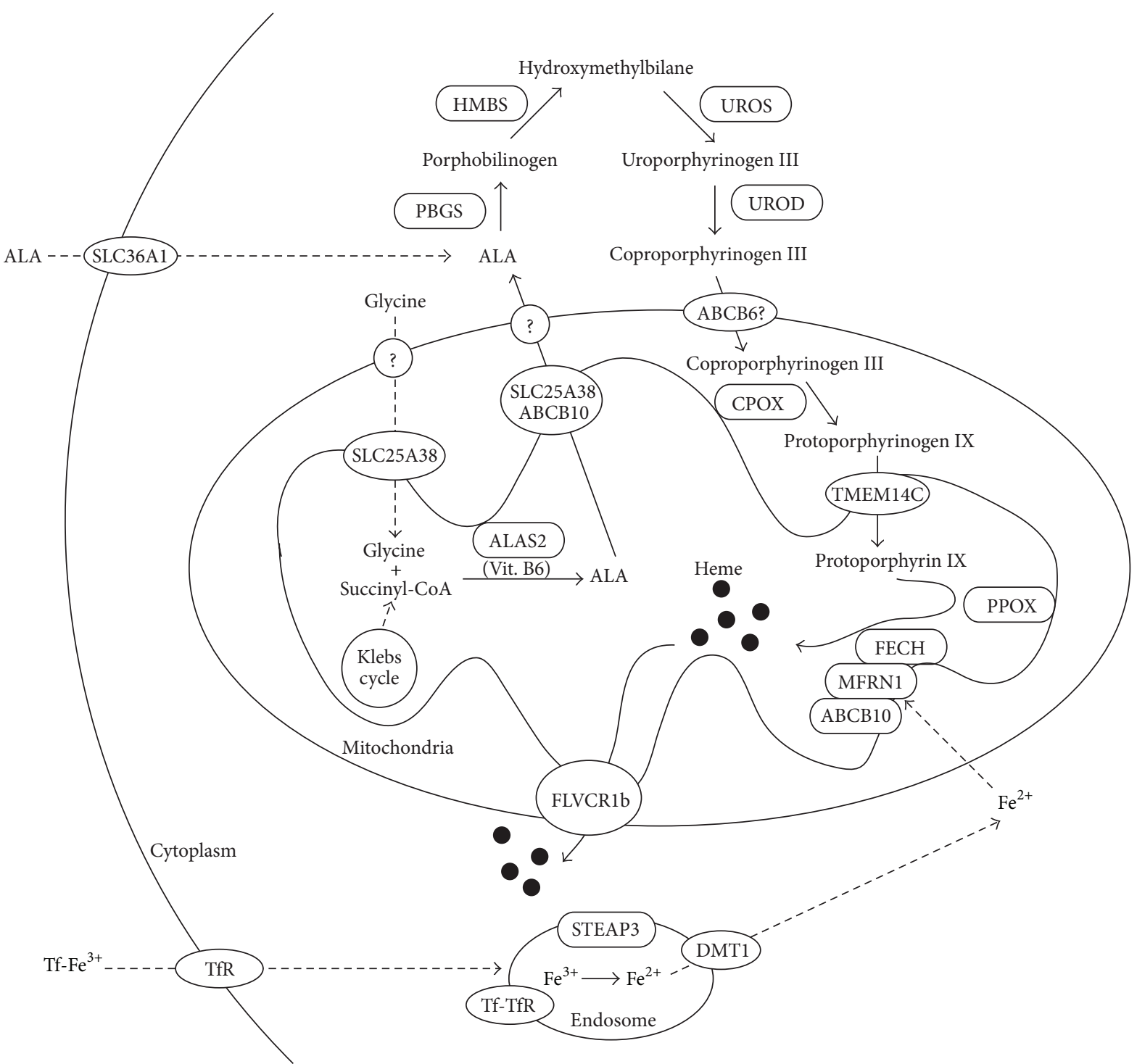

FIGURE 1: Heme biosynthetic pathway in erythroid cells. Schematic representation of the heme biosynthetic pathway in erythroid cells. Heme synthesis begins with the condensation of glycine and succinyl-CoA to form ALA. Next, ALA is transported outside of the mitochondria and catalyzed to form coproporphyrinogen III. CPOX converts coproporphyrinogen III to protoporphyrinogen IX, which is subsequently oxidized into protoporphyrin IX by PPOX. Finally, ferrous iron is incorporated into protoporphyrinogen IX to form heme in a reaction catalyzed by FECH. FECH is localized in the inner mitochondrial membrane and associates with MFRN1 and ABCB10. SLC25A38 and $\mathrm{ABCB} 10$ have been proposed as mitochondrial ALA exporters located on the inner mitochondrial membrane. ABCB6 and TMEM14C have been proposed as putative coproporphyrinogen III and protoporphyrinogen IX importers, respectively. FLVCR1b is a mitochondrial heme exporter. Tf-bound $\mathrm{Fe}^{3+}$ is bound to TfR, released into endosome, and reduced to $\mathrm{Fe}^{2+}$ by STEAP3. Subsequently, $\mathrm{Fe}^{2+}$ exits the endosome via DMT1 and enters the mitochondria via MFRN1. ALAS2: erythroid-specific $\delta$-aminolevulinate synthase, ALA: $\delta$-aminolevulinic acid, PBGS: porphobilinogen synthase, HMBS: hydroxymethylbilane synthase, UROS: uroporphyrinogen synthase, UROD: uroporphyrinogen decarboxylase, CPOX: coproporphyrinogen oxidase, PPOX: protoporphyrinogen IX oxidase, FECH: ferrochelatase, MFRN1: mitoferrin 1, Vit. B6: vitamin B6, SLC25A38: solute carrier family 25 member 38, ABCB10: ATP-binding cassette subfamily B member 10, TMEM14C: transmembrane protein 14C, FLVCR1b: feline leukemia virus subgroup C receptor, Tf: transferrin, TfR: transferrin receptor, STEAP3: sixtransmembrane epithelial antigen of prostate 3, and DMT1: divalent metal transporter 1. Adapted and modified from [12-14].

exist for HMBS and UROS. The housekeeping HMBS contains an additional 17 amino acid residues at the amino terminus as compared to the erythroid form of the protein; in contrast, the housekeeping and erythroid UROS proteins are identical.
Coproporphyrin III enters the mitochondria, where it is oxidatively decarboxylated by coproporphyrinogen oxidase (CPOX) to form protoporphyrinogen IX. Protoporphyrinogen IX is then oxidized to protoporphyrin IX by protoporphyrinogen oxidase (PPOX). Finally, ferrous iron is inserted 
into protoporphyrin IX by ferrochelatase (FECH) to form heme. FECH is another rate-limiting enzyme of the heme biosynthetic pathway. This enzyme exists as a homodimer in which each subunit contains a $[2 \mathrm{Fe}-2 \mathrm{~S}]$ cluster that is necessary for the enzymatic activity [15]. In addition, FECH expression is induced during erythroid differentiation, wherein it is controlled by the Sp1, NF-E2, and GATA elements [16].

Heme biosynthesis, therefore, also relies on the intracellular availability of iron. In erythroid cells, iron is acquired via transferrin receptor-mediated endocytosis of circulating transferrin-iron (III) $\left(\mathrm{Fe}^{3+}\right)$ complexes. Once internalized, transferrin-bound $\mathrm{Fe}^{3+}$ is released, reduced to $\mathrm{Fe}^{2+}$ by six-transmembrane epithelial antigen of the prostate 3 (STEAP3) [17], exits the endosome via divalent metal transporter 1 (DMT1), and subsequently enters the mitochondria. The inner mitochondrial membrane protein mitoferrin 1 (MFRN1) plays an important role in supplying iron for heme biosynthesis as well as iron-sulfur clusters in the mitochondria [18]. MFRN1 is responsible for iron transport into the mitochondria, although the presence of another inner membrane protein, $\mathrm{ABCB} 10$, is required to stabilize MFRN1 [19]. Although the precise role of ABCB10 has yet to be elucidated, MFRN1 forms a complex with FECH and $\mathrm{ABCB} 10$ that might allow the direct transfer of ferrous iron for heme and/or iron-sulfur cluster synthesis [20].

\section{Transport of Heme and Porphyrin Intermediates}

As described above, heme biosynthetic enzymes are fairly well understood. However, relatively less is known about the transport of heme and porphyrin intermediates. The following describes the recent understanding regarding the transport of heme and porphyrin intermediates (Figure 1).

Glycine is required for the first step of porphyrin synthesis and must be transported from the cytosol into the mitochondria. Solute carrier family 25 member 38 (SLC25A38) was recently identified through the positional cloning of a gene implicated in nonsyndromic congenital sideroblastic anemia [21]. Yeast lacking the SLC25A38 ortholog YDL119c exhibits a defect in ALA biogenesis [21], suggesting that SLC25A38 is required for glycine import. The ability of SLC25A38 and $\mathrm{ABCB} 10$ to export ALA from mitochondria has also been proposed (Figure 1) [3]. Because both SLC25A38 and $\mathrm{ABCB} 10$ are located in the inner mitochondrial membrane, it remains to be elucidated how ALA could be exported through the outer membrane. However, extracellular ALA can be supplied across the plasma membrane for heme biosynthesis. Among the ALA transporters, SLC36A1 is abundantly expressed in erythroid cells (Figure 1) [22]. However, the significance of extracellular ALA with respect to erythropoiesis and normal erythroid differentiation remains to be elucidated.

In the cytosol, ALA is converted to coproporphyrinogen III, which is subsequently transported to the mitochondrial intermembrane space. Several studies have suggested that adenosine triphosphate- (ATP-) binding cassette, subfamily $\mathrm{B}$ member 6 (ABCB6), which is located in the mitochondrial outer membrane, is responsible for coproporphyrinogen III transport $[23,24]$. However, these findings remain controversial because ABCB6 has also been detected in the plasma membrane, Golgi, and lysosomes [25-27] and is even used to define the blood group Langereis [28]. In addition, a defect in ABCB6 can cause inherited developmental defects of the eye (ocular coloboma) [29] and skin (dyschromatosis universalis hereditaria) [30]. Nevertheless, ABCB6 expression is obviously induced during erythroid differentiation $[3,4,31]$, suggesting that it may play an important role in erythropoiesis and indicating a need for further analyses.

Recently, a large-scale screening was conducted to identify mitochondrial proteins that are coexpressed with the core machinery of heme biosynthesis [31]. One of these genes, transmembrane protein 14C (TMEM14C), encodes the mitochondrial inner membrane protein, which is essential for erythropoiesis in zebrafish and mice [12, 31]. Functional analyses have suggested the involvement of TMEM14C in the import of protoporphyrinogen IX into the mitochondrial matrix for heme synthesis and subsequent hemoglobin production [12]. Despite its essential role during erythropoiesis, human disorders resulting from defects in TMEM14C have not yet been identified. Another mitochondrial gene, solute carrier family 25 member 39 (SLC25A39), is required for heme synthesis in yeast, zebrafish, and mammalian erythroid cells [31]. However, the exact role of SLC25A39 in mammalian erythropoiesis requires further investigation.

In mammals, the membrane protein feline leukemia virus, subgroup C receptor 1, SLC49A1 (FLVCR1) was recently identified as a heme exporter. There are two different isoforms of FLVCR1, FLVCR1a and FLVCR1b, which are expressed on the plasma membrane and the mitochondria, respectively [32-34]. Recent studies have revealed that the mitochondrial heme exporter FLVCR1b, which contains shortened Nterminus resulting from an alternative transcriptional start site (in contrast to originally identified FLVCR1a), is essential for erythroid differentiation [34]. On the other hand, targeted disruption of Flvcrla resulted in skeletal defects and vascular abnormalities but not anemia, implying that FLVCRla is dispensable for erythropoiesis [3]. A closely related homologue, FLVCR2 (SLC49A2), was reported to be ubiquitously expressed membrane-attached heme importer [35]. However, the physiological roles of FLVCR2 in erythropoiesis remain to be elucidated [5].

\section{Heme Is Involved in Several Biological Processes during Erythroid Differentiation}

In addition to acting as a prosthetic group in hemoproteins such as hemoglobin, heme itself might affect several biological processes during erythroid differentiation, including transcription, translation, protein degradation, and microRNA (miRNA) processing $[1,36,37]$. Heme modifies the function or localization of its target proteins through direct binding to $\mathrm{CP}$ motifs, which consist of cysteine and proline residues $[1,36,37]$. CP motif-containing proteins, namely, hemebinding proteins, reportedly include heme activator protein 1 (Hap1), BTB and CNC homology 1, basic leucine zipper transcription factor $1(\mathrm{BACH} 1)$ and $\mathrm{BACH} 2, \mathrm{ALAS1}$, ALAS2, 
heme oxygenase 2 (HO-2), iron-responsive element-binding protein 2 (IRP2), heme-oxidized IRP2 ubiquitin ligase-1 (HOIL-1), and heme regulated inhibitor (HRI) [37, 38].

$\mathrm{BACH} 1$ is a basic leucine zipper transcriptional repressor that can bind members of the small Maf family through its Maf recognition element (MARE) to form heterodimers [37, 39]. Binding of heme to $\mathrm{CP}$ motifs within $\mathrm{BACH} 1$ inhibits the DNA-binding ability of BACH1, induces its dissociation from small Maf proteins, triggers its export from the nucleus, and induces its ubiquitination and degradation [39-42]. Therefore, whereas the BACH1-small Maf heterodimer formed via MARE site binding suppresses target gene transcription, heme displaces BACH1, allowing small Maf to heterodimerize with nuclear factor, erythroid 2 (p45 NF-E2), or nuclear factor, erythroid 2-like 2 (NRF2) via the MARE site, resulting in transcriptional activation [37]. In erythroid cells, BACH1 directly regulates the expression of globins [43] and HO-1 [44], suggesting an important role for BACH1 in erythroid differentiation as well as heme metabolism. Beyond erythroid cells, BACH1 also regulates the expression of ferroportin [45], ferritins [46], and SPI-C, which promotes monocyte differentiation to iron-recycling macrophages [47], and thus suggests a role for BACH1 in systemic iron homeostasis. Other heme regulated transcriptional regulators include Drosophila melanogaster E75 and its mammalian homologue $\operatorname{Rev}-\operatorname{Erb} \alpha / \beta$, both of which belong to the nuclear hormone receptor superfamily and can bind heme via their respective ligand-binding domains [37, 48, 49].

Heme also controls target gene translation by binding to the two heme-binding domains of HRI, a known protein kinase [50]. HRI is autophosphorylated at multiple sites under conditions of heme deficiency, an essential process for kinase activity $[51,52]$. Under conditions of heme deficiency, HRI inhibits mRNA translation by phosphorylating the $\alpha$ subunit of the eukaryotic initiation factor (eIF2 $\alpha$ ) [50], whereas an increased heme concentration during erythroid differentiation inhibits HRI activity, thereby promoting the translation of $\alpha$-and $\beta$-globins [53, 54]. Developing erythroid cells synthesize enormous amounts of hemoglobin but must synthesize the correct amounts of globin proteins and heme because of the intrinsic toxicities of these molecules; for example, excess globins cause proteotoxicity [54,55], whereas free heme is a potent oxidative molecule that can produce reactive oxygen species (ROS) via the Fenton reaction [56]. Therefore, it appears reasonable to consider that heme contributes to the coordination of globin and heme syntheses.

As previously described, heme participates in transcriptional regulation through binding to $\mathrm{BACH} 1$ and inducing its ubiquitination and subsequent degradation [37, 42], which can be considered another regulatory action of heme. In addition, the IRP-IRE system has been shown to posttranscriptionally regulate the expression of several mRNAs, including those encoding ALAS2, transferrin receptor, ferroportin, DMT1, and ferritin, thus playing an important role in iron homeostasis (reviewed in $[1,57]$ ). IRPs comprise two independent proteins, IRP1 and IRP2, the latter of which predominantly regulates iron homeostasis in vivo [58]. Interestingly, heme binds to IRP2 through the CP motif within the iron dependent degradation (IDD) domain to induce its ubiquitination/degradation $[59,60]$. Therefore, the regulatory processes of heme biosynthesis and iron metabolism in erythroid cells appear to be closely related.

Finally, recent reports have revealed that heme also regulates the processing of a class of noncoding RNAs (ncRNAs) that includes housekeeping RNAs (rRNAs, tRNAs, and snoRNAs), small and long ncRNAs ( $<200$ and $>200$ bases, resp.), small interfering RNAs (siRNAs), PIWI-interacting RNAs (piRNAs), and miRNAs [61]. miRNAs are now universally recognized as an extensive and ubiquitous class of regulatory molecules [62]. Heme binds to the cysteine residue at amino acid position of 352 of the RNA-binding protein DiGeorge critical region 8 (DGCR8) and induces the dimerization of DGCR8, thereby promoting the processing of pri-miRNA into mature miRNA $[63,64]$. Whereas the role of miRNAs during erythroid differentiation is well understood [65], the significance of heme-mediated miRNA processing during erythroid differentiation remains to be elucidated and thus requires further investigation.

\section{Disorders Resulting from Defective Heme Biosynthesis in Erythroid Cells}

Heme is mainly produced by erythroblasts and hepatocytes. Whereas heme negatively regulates the expression of ALAS1 via a feedback mechanism in nonerythroid cells (hepatocytes) [1], it does not negatively regulate ALAS2 in erythroblasts; in fact, heme can promote its own synthesis by regulating ALAS2 expression through the IRP-IRE system. Therefore, the regulation of heme biosynthesis should be considered separately in erythroid and nonerythroid cells. In addition, a defect in any heme biosynthetic enzyme does not result in uniform systematic consequences [2]. For example, defects in PBGS or HMBS impair heme biosynthesis in the liver, leading to the onset of ALA dehydratase deficiency porphyria (ADP) or acute intermittent porphyria (AIP), respectively, whereas no abnormality is observed in erythroblasts. On the other hand, defects in FECH or UROS do not severely impair heme biosynthesis in the liver but instead result in the onset of erythropoietic protoporphyria (EPP) or congenital erythropoietic porphyria (CEP). Accordingly, each disorder is referred to as either hepatic or erythropoietic porphyria.

This review mainly focuses on hematologically relevant human disorders resulting from defects in heme biosynthesis, such as sideroblastic anemia and erythropoietic porphyria.

4.1. Sideroblastic Anemia. Sideroblastic anemias are a heterogenous group of syndromic and nonsyndromic disorders with the common features of mitochondrial iron accumulation in bone marrow erythroid precursors (ring sideroblasts), ineffective erythropoiesis, increased tissue iron levels, and varying proportions of hypochromic erythrocytes in the peripheral blood [13, 66, 67]. Whereas these syndromes are commonly acquired and predominantly associated with myelodysplastic syndrome, of which a significant portion of cases might result from a mutation in the RNA splicing machinery componentsplicing factor $3 \mathrm{~b}$, subunit 1 (SF3B1) [68], congenital forms of sideroblastic anemia (CSA) have been reported; it is a rare and heterogeneous disease caused 
TABLE 1: Genetic features of congenital sideroblastic anemias.

\begin{tabular}{lcccc}
\hline & Inheritance & Chromosome & Gene & Treatment \\
\hline XLSA & X-linked & Xp11.21 & ALAS2 & Vitamin B6 \\
XLSA/A & X-linked & Xp13.3 & ABCB7 & GLRX5 \\
SA/GLRX5 & Recessive & $14 \mathrm{q} 32.13$ & SLC25A38 \\
SA/SLC25A38 & Recessive & $3 \mathrm{p} 22.1$ & STEAP3 \\
SA/STEAP3 & $?$ & $2 \mathrm{q} 14.2$ & Mitochondrial \\
PMPS & Maternal & Mitochondria & SLC19A2 & PUS1 \\
TRMA & Recessive & $1 \mathrm{q} 24.2$ & Thiamine \\
MLASA/PUS1 & Recessive & $12 \mathrm{q} 24.33$ & YARS2 & - \\
MLASA/YARS2 & Recessive & $12 \mathrm{p} 11.21$ & TRNT1 \\
SIFD/TRNT1 & Recessive & $3 \mathrm{p} 26.2$ & - \\
\hline
\end{tabular}

XLSA: X-linked sideroblastic anemia; XLSA/A: X-linked sideroblastic anemia with ataxia; PMPS: Pearson Marrow Pancreas Syndrome; TRMA: thiamineresponsive megaloblastic anemia; MLASA: mitochondrial myopathy and sideroblastic anemia. SIFD: syndromic form of congenital sideroblastic anemia associated with B-cell immunodeficiency, periodic fevers, and developmental delay. Adopted and modified from [13, 14]. ${ }^{*}$ Sporadic cases are also observed.

by mutations of genes involved in heme biosynthesis (ALAS2, SLC25A38), iron-sulfur [Fe-S] cluster biosynthesis (ABCB7, GLRX5), iron reduction (STEAP3), and mitochondrial protein synthesis (mitochondrial DNA, PUS1, YARS2, TRNT1, and SLC19A2) (described in $[20,66,67,69-72])$ (Table 1).

4.1.1. X-Linked Sideroblastic Anemia. The most common form of CSA is XLSA (X-linked sideroblastic anemia), which is attributed to mutations in the X-linked gene ALAS2 [1, 73]. Defects in ALAS2 result in decreased protoporphyrin synthesis and subsequent reductions in iron incorporation and heme synthesis, leading to microcytic anemia and the appearance of ring sideroblasts in the bone marrow. Typically, XLSA patients are male and present before the age of 40 years; however, this disorder occurs across a broad range of ages and can affect elderly patients [74]. On the other hand, anemia may also present in heterozygous female carriers, presumably because of skewed $\mathrm{X}$ inactivation or the excessive age-related skewing that occurs in hematopoietic tissues $[75,76]$.

Most of the XLSA-associated mutations in ALAS2 are missense substitutions resulting in loss of functionality [20, $67,69,77,78]$, whereas mutations in the ALAS2 regulatory region, such as the promoter [79] and intron $1[8,9,80]$, lead to decreased ALAS2 expression. ALAS2 missense mutations commonly decrease the binding of pyridoxal $5^{\prime}$-phosphate (PLP, vitamin B6), which is a cofactor for ALAS2 enzymatic activity, thus accounting for the PLP responsiveness in XLSA patients carrying such mutations [7, 81]. However, nearly half of XLSA cases are unresponsive to PLP [13, 82]. In such cases, ALA supplementation might mitigate these impairments [22]. In our recent preclinical in vitro analysis, ALA restores defects in ALAS2 deficiency based on human induced pluripotent stem (iPS) cell-derived erythroblasts [22]. Because ALA is an endogenous amino acid that has been shown to be safe in clinical settings [83], it might be considered to administer ALA in patients with XLSA who are refractory to PLP supplementation.

4.2. Erythropoietic Porphyria. Erythropoietic porphyria includes both erythropoietic protoporphyria and congenital erythropoietic porphyria. The former comprises two variants, erythropoietic protoporphyria (EPP) and X-linked protoporphyria (XLPP), and is classified among the cutaneous porphyrias characterized by the accumulation of protoporphyrin IX, which results in photosensitivity. EPP and XLPP are clinically indistinguishable but result from the mutations of different genes: FECH and ALAS2, respectively.

4.2.1. Erythropoietic Protoporphyria (EPP). EPP is an inherited disorder caused by a partial deficiency in $\mathrm{FECH}$ activity $[2,84]$. In this disorder, protoporphyrin accumulates in the erythroblasts and is subsequently taken up by the liver and skin. Cutaneous photosensitivity characteristically begins in childhood in the absence of neurological involvement $[2,84]$. Liver damage is observed in patients with severe symptoms [84]. In addition, hypochromic microcytic anemia occurs in $20-60 \%$ of cases [85], and ring sideroblasts may be observed [86]. Elevated levels of erythrocyte protoporphyrin are observed. However, in contrast to iron deficiency anemia and lead poisoning, in which the increased erythrocyte protoporphyrin is chelated with zinc, erythrocytic protoporphyrin in EPP remains in a free state [87].

The inheritance of EPP is considered autosomal recessive but is a bit unusual. In most patients, EPP results from the coinheritance of a specific FECH mutation in trans with a hypomorphic low-expression $\mathrm{FECH}$ polymorphism (IVS3-48C) [88]. The IVS3-48C allele of this polymorphism increases the use of an aberrant splicing site that may contribute to disease onset [89]. Ethnic differences have been reported in the frequency of the IVS3-48C allele; specifically, the frequency of this allele differs widely among Japanese (43\%), southeast Asian (31\%), white French (11\%), North African $(2.7 \%)$, and black West African $(<1 \%)$ populations [89].

Besides avoiding exposure to sunlight, the treatment for EPP includes the oral administration of $\beta$-carotene and afamelanotide, transfusion of cholestyramine red cells, and, in severe cases, liver transplantation [2,90]. Low-dose intravenous iron therapy may also be effective [91]. 
4.2.2. X-Linked Protoporphyria (XLPP). XLPP is a clinically indistinguishable X-linked form of EPP caused by gain-offunction mutations in ALAS2 [92]. This gain-of-function of ALAS2 increases protoporphyrin IX production in the context of normal FECH activity, the latter of which becomes rate-limiting and presumably leads to the onset of the EPPlike disease phenotype. In contrast to EPP, in XLPP the erythrocyte levels of both zinc protoporphyrin and free protoporphyrin are increased. This disease is similar but not identical to that described in $\operatorname{Irp} 2^{-/-}$mice, which are characterized by the overexpression of ALAS2 consequent to the loss of IRP2-dependent translational repression [93].

Mutations of ALAS2 include c.1706-1709 delAGTG (p.E569GfsX24) and c1699-1700 delAT (p.M567EfsX2), which result in frameshifts that cause replacement or deletion of 19-20 carboxy-terminal residues from ALAS2 [93]. Recently, the novel ALAS2 mutations c.1734 delG and c.1642 C > T (p.Q548X) have been identified [94]. The treatment of XLPP is similar to that of the biochemically and phenotypically similar EPP.

4.2.3. Congenital Erythropoietic Porphyria (CEP). CEP is an autosomal recessive erythropoietic porphyria characterized by severe photosensitivity and hemolytic anemia [2]. This disease results from a mutation in the UROS gene, and recent work has suggested that an accompanying gain-of-function mutation in ALAS2 could modify the disease severity [95]. In addition, an X-linked form of CEP has been reported in which a trans-acting GATA-1-R216W mutation contributes to the onset of CEP [96].

\section{Conclusion}

Elucidation of heme biology in the mammalian erythroid cell would provide an important insight to understand and to get more efficient targets for the human disorders that arise from defective heme synthesis.

\section{Conflict of Interests}

Drs. Fujiwara and Harigae received a research grant from Chugai Pharmaceutical Co., Ltd.

\section{References}

[1] K. Furuyama, K. Kaneko, and P. D. Vargas, "Heme as a magnificent molecule with multiple missions: heme determines its own fate and governs cellular homeostasis," The Tohoku Journal of Experimental Medicine, vol. 213, no. 1, pp. 1-16, 2007.

[2] S. Sassa, "Modern diagnosis and management of the porphyrias," British Journal of Haematology, vol. 135, no. 3, pp. 281-292, 2006.

[3] D. Chiabrando, S. Mercurio, and E. Tolosano, "Heme and erythropoieis: more than a structural role," Haematologica, vol. 99, no. 6, pp. 973-983, 2014.

[4] H. A. Dailey and P. N. Meissner, "Erythroid heme biosynthesis and its disorders," Cold Spring Harbor Perspectives in Medicine, vol. 3, no. 4, 2013.
[5] J. Chung, C. Chen, and B. H. Paw, "Heme metabolism and erythropoiesis," Current Opinion in Hematology, vol. 19, no. 3, pp. 156-162, 2012.

[6] P. D. Cotter, H. A. Drabkin, T. Varkony, D. I. Smith, and D. F. Bishop, "Assignment of the human housekeeping $\delta$ aminolevulinate synthase gene (ALAS1) to chromosome band 3p21.1 by PCR analysis of somatic cell hybrids," Cytogenetics and Cell Genetics, vol. 69, no. 3-4, pp. 207-208, 1995.

[7] P. D. Cotter, H. F. Willard, J. L. Gorski, and D. F. Bishop, "Assignment of human erythroid $\delta$-aminolevulinate synthase (ALAS2) to a distal subregion of band Xp11.21 by PCR analysis of somatic cell hybrids containing X; Autosome translocations," Genomics, vol. 13, no. 1, pp. 211-212, 1992.

[8] T. Fujiwara, H. O'Geen, S. Keles et al., "Discovering hematopoietic mechanisms through genome-wide analysis of GATA factor chromatin occupancy," Molecular Cell, vol. 36, no. 4, pp. 667681, 2009.

[9] K. Kaneko, K. Furuyama, T. Fujiwara et al., "Identification of a novel erythroid-specific enhancer for the ALAS2 gene and its loss-of-function mutation which is associated with congenital sideroblastic anemia," Haematologica, vol. 99, no. 2, pp. 252-261, 2014.

[10] P. T. Erskine, N. Senior, S. Awan et al., "X-ray structure of 5-aminolaevulinate dehydratase, a hybrid aldolase," Nature Structural Biology, vol. 4, no. 12, pp. 1025-1031, 1997.

[11] A. H. Kaya, M. Plewinska, D. M. Wong, R. J. Desnick, and J. G. Wetmur, "Human $\delta$-aminolevulinate dehydratase (ALAD) gene: structure and alternative splicing of the erythroid and housekeeping mRNAs," Genomics, vol. 19, no. 2, pp. 242-248, 1994.

[12] Y. Y. Yien, R. F. Robledo, I. J. Schultz et al., "TMEM14C is required for erythroid mitochondrial heme metabolism," Journal of Clinical Investigation, vol. 124, no. 10, pp. 4294-4304, 2014.

[13] T. Fujiwara and H. Harigae, "Pathophysiology and genetic mutations in congenital sideroblastic anemia," Pediatrics International, vol. 55, no. 6, pp. 675-679, 2013.

[14] T. Fujiwara and H. Harigae, "Update on the biology of heme synthesis in erythroid cells," Rinsho Ketsueki, vol. 56, no. 2, pp. 119-127, 2015.

[15] C.-K. Wu, H. A. Dailey, J. P. Rose, A. Burden, V. M. Sellers, and B.-C. Wang, "The $2.0 \AA$ structure of human ferrochelatase, the terminal enzyme of heme biosynthesis," Nature Structural \& Molecular Biology, vol. 8, no. 2, pp. 156-160, 2001.

[16] A. Tugores, S. T. Magness, and D. A. Brenner, "A single promoter directs both housekeeping and erythroid preferential expression of the human ferrochelatase gene," The Journal of Biological Chemistry, vol. 269, no. 49, pp. 30789-30797, 1994.

[17] R. S. Ohgami, D. R. Campagna, E. L. Greer et al., "Identification of a ferrireductase required for efficient transferrin-dependent iron uptake in erythroid cells," Nature Genetics, vol. 37, no. 11, pp. 1264-1269, 2005.

[18] G. C. Shaw, J. J. Cope, L. Li et al., "Mitoferrin is essential for erythroid iron assimilation," Nature, vol. 440, no. 7080, pp. 96$100,2006$.

[19] W. Chen, P. N. Paradkar, L. Li et al., "Abcb10 physically interacts with mitoferrin-1 (Slc25a37) to enhance its stability and function in the erythroid mitochondria," Proceedings of the National Academy of Sciences of the United States of America, vol. 106, no. 38, pp. 16263-16268, 2009. 
[20] M. D. Fleming, "Congenital sideroblastic anemias: iron and heme lost in mitochondrial translation," Hematology/the Education Program of the American Society of Hematology, vol. 2011, pp. 525-531, 2011.

[21] D. L. Guernsey, H. Jiang, D. R. Campagna et al., "Mutations in mitochondrial carrier family gene SLC25A38 cause nonsyndromic autosomal recessive congenital sideroblastic anemia," Nature Genetics, vol. 41, no. 6, pp. 651-653, 2009.

[22] T. Fujiwara, K. Okamoto, R. Niikuni et al., "Effect of 5aminolevulinic acid on erythropoiesis: a preclinical in vitro characterization for the treatment of congenital sideroblastic anemia," Biochemical and Biophysical Research Communications, vol. 454, no. 1, pp. 102-108, 2014.

[23] P. C. Krishnamurthy, G. Du, Y. Fukuda et al., "Identification of a mammalian mitochondrial porphyrin transporter," Nature, vol. 443, no. 7111, pp. 586-589, 2006.

[24] P. Krishnamurthy and J. D. Schuetz, "The role of ABCG2 and ABCB6 in porphyrin metabolism and cell survival," Current Pharmaceutical Biotechnology, vol. 12, no. 4, pp. 647-655, 2011.

[25] J. K. Paterson, S. Shukla, C. M. Black et al., "Human ABCB6 localizes to both the outer mitochondrial membrane and the plasma membrane," Biochemistry, vol. 46, no. 33, pp. 9443-9452, 2007.

[26] M. Tsuchida, Y. Emi, Y. Kida, and M. Sakaguchi, "Human $\mathrm{ABC}$ transporter isoform $\mathrm{B} 6$ ( $\mathrm{ABCB} 6)$ localizes primarily in the Golgi apparatus," Biochemical and Biophysical Research Communications, vol. 369, no. 2, pp. 369-375, 2008.

[27] K. Kiss, A. Brozik, N. Kucsma et al., "Shifting the paradigm: the putative mitochondrial protein ABCB6 resides in the lysosomes of cells and in the plasma membrane of erythrocytes," PLoS ONE, vol. 7, no. 5, Article ID e37378, 2012.

[28] V. Helias, C. Saison, B. A. Ballif et al., "ABCB6 is dispensable for erythropoiesis and specifies the new blood group system Langereis," Nature Genetics, vol. 44, no. 2, pp. 170-173, 2012.

[29] L. Wang, F. He, J. Bu et al., "ABCB6 mutations cause ocular coloboma," The American Journal of Human Genetics, vol. 90, no. 1, pp. 40-48, 2012.

[30] H. Liu, Y. Li, K. K. Hung et al., "Genome-wide linkage, exome sequencing and functional analyses identify $A B C B 6$ as the pathogenic gene of dyschromatosis universalis hereditaria," PLoS ONE, vol. 9, no. 2, Article ID e87250, 2014.

[31] R. Nilsson, I. J. Schultz, E. L. Pierce et al., "Discovery of genes essential for heme biosynthesis through large-scale gene expression analysis," Cell Metabolism, vol. 10, no. 2, pp. 119-130, 2009.

[32] J. G. Quigley, Z. Yang, M. T. Worthington et al., "Identification of a human heme exporter that is essential for erythropoiesis," Cell, vol. 118, no. 6, pp. 757-766, 2004.

[33] S. B. Keel, R. T. Doty, Z. Yang et al., "A heme export protein is required for red blood cell differentiation and iron homeostasis," Science, vol. 319, no. 5864, pp. 825-828, 2008.

[34] D. Chiabrando, S. Marro, S. Mercurio et al., "The mitochondrial heme exporter FLVCR1b mediates erythroid differentiation," Journal of Clinical Investigation, vol. 122, no. 12, pp. 4569-4579, 2012.

[35] S. P. Duffy, J. Shing, P. Saraon et al., "The Fowler syndromeassociated protein FLVCR2 is an importer of heme," Molecular and Cellular Biology, vol. 30, no. 22, pp. 5318-5324, 2010.

[36] J. T. Lathrop and M. P. Timko, "Regulation by heme of mitochondrial protein transport through a conserved amino acid motif," Science, vol. 259, no. 5094, pp. 522-525, 1993.
[37] K. Igarashi and M. Watanabe-Matsui, "Wearing red for signaling: the heme-bach axis in heme metabolism, oxidative stress response and iron immunology," The Tohoku Journal of Experimental Medicine, vol. 232, no. 4, pp. 229-253, 2014.

[38] H. Harigae, T. Fujiwara, and K. Furuyama, "Heme metabolism and anemia," Rinsho Ketsueki, vol. 55, no. 7, pp. 729-734, 2014.

[39] T. Oyake, K. Itoh, H. Motohashi et al., "Bach proteins belong to a novel family of BTB-basic leucine zipper transcription factors that interact with MafK and regulate transcription through the NF-E2 site," Molecular and Cellular Biology, vol. 16, no. 11, pp. 6083-6095, 1996.

[40] K. Ogawa, J. Sun, S. Taketani et al., "Heme mediates derepression of Maf recognition element through direct binding to transcription repressor Bachl," The EMBO Journal, vol. 20, no. 11, pp. 2835-2843, 2001.

[41] H. Suzuki, S. Tashiro, S. Hira et al., "Heme regulates gene expression by triggering Crml-dependent nuclear export of Bachl," The EMBO Journal, vol. 23, no. 13, pp. 2544-2553, 2004.

[42] Y. Zenke-Kawasaki, Y. Dohi, Y. Katoh et al., "Heme induces ubiquitination and degradation of the transcription factor Bach1," Molecular and Cellular Biology, vol. 27, no. 19, pp. 69626971, 2007.

[43] T. Tahara, J. Sun, K. Nakanishi et al., "Heme positively regulates the expression of $\beta$-globin at the locus control region via the transcriptional factor Bach1 in erythroid cells," The Journal of Biological Chemistry, vol. 279, no. 7, pp. 5480-5487, 2004.

[44] J. Sun, M. Brand, Y. Zenke, S. Tashiro, M. Groudine, and K. Igarashi, "Heme regulates the dynamic exchange of Bachl and NF-E2-related factors in the Maf transcription factor network," Proceedings of the National Academy of Sciences of the United States of America, vol. 101, no. 6, pp. 1461-1466, 2004.

[45] S. Marro, D. Chiabrando, E. Messana et al., "Heme controls ferroportin1 (FPN1) transcription involving Bach1, Nrf2 and a MARE/ARE sequence motif at position -7007 of the FPN1 promoter," Haematologica, vol. 95, pp. 1261-1268, 2010.

[46] K. J. Hintze, Y. Katoh, K. Igarashi, and E. C. Theil, "Bach1 repression of ferritin and thioredoxin reductasel is hemesensitive in cells and in vitro and coordinates expression with heme oxygenasel, $\beta$-globin, and $\operatorname{NADP}(\mathrm{H})$ quinone (Oxido) reductasel," The Journal of Biological Chemistry, vol. 282, no. 47, pp. 34365-34371, 2007.

[47] M. Haldar, M. Kohyama, A. Y.-L. So et al., "Heme-mediated SPI-C induction promotes monocyte differentiation into ironrecycling macrophages," Cell, vol. 156, no. 6, pp. 1223-1234, 2014.

[48] J. Reinking, M. M. S. Lam, K. Pardee et al., "The Drosophila nuclear receptor E75 contains heme and is gas responsive," Cell, vol. 122, no. 2, pp. 195-207, 2005.

[49] N. Wu, L. Yin, E. A. Hanniman, S. Joshi, and M. A. Lazar, "Negative feedback maintenance of heme homeostasis by its receptor, Rev-erb $\alpha$," Genes \& Development, vol. 23, no. 18, pp. 2201-2209, 2009.

[50] J.-J. Chen, M. S. Throop, L. Gehrke et al., "Cloning of the cDNA of the heme-regulated eukaryotic initiation factor $2 \alpha$ (eIF- $2 \alpha$ ) kinase of rabbit reticulocytes: homology to yeast GCN2 protein kinase and human double-stranded-RNA-dependent eIF- $2 \alpha$ kinase," Proceedings of the National Academy of Sciences of the United States of America, vol. 88, no. 17, pp. 7729-7733, 1991.

[51] B. N. Bauer, M. Rafie-Kolpin, L. Lu, A. Han, and J.-J. Chen, "Multiple autophosphorylation is essential for the formation of the active and stable homodimer of heme-regulated eIF $2 \alpha$ kinase," Biochemistry, vol. 40, no. 38, pp. 11543-11551, 2001. 
[52] M. Rafie-Kolpin, A.-P. Han, and J.-J. Chen, "Autophosphorylation of threonine 485 in the activation loop is essential for attaining eIF $2 \alpha$ kinase activity of HRI," Biochemistry, vol. 42, no. 21, pp. 6536-6544, 2003.

[53] J.-J. Chen, "Translational control by heme-regulated eIF2 $\alpha$ kinase during erythropoiesis," Current Opinion in Hematology, vol. 21, no. 3, pp. 172-178, 2014.

[54] A.-P. Han, C. Yu, L. Lu et al., "Heme-regulated eIF2 $\alpha$ kinase (HRI) is required for translational regulation and survival of erythroid precursors in iron deficiency," The EMBO Journal, vol. 20, no. 23, pp. 6909-6918, 2001.

[55] A.-P. Han, M. D. Fleming, and J.-J. Chen, "Heme-regulated eIF2alpha kinase modifies the phenotypic severity of murine models of erythropoietic protoporphyria and betathalassemia," The Journal of Clinical Investigation, vol. 115, no. 6, pp. 1562-1570, 2005.

[56] T.-W. Yu and D. Anderson, "Reactive oxygen species-induced DNA damage and its modification: a chemical investigation," Mutation Research, vol. 379, no. 2, pp. 201-210, 1997.

[57] N. Wilkinson and K. Pantopoulos, "The IRP/IRE system in vivo: insights from mouse models," Frontiers in Pharmacology, vol. 5, article 176, 2014.

[58] E. G. Meyron-Holtz, M. C. Ghosh, and T. A. Rouault, "Mammalian tissue oxygen levels modulate iron-regulatory protein activities in vivo," Science, vol. 306, no. 5704, pp. 2087-2090, 2004.

[59] K. Iwai, R. D. Klausner, and T. A. Rouault, "Requirements for iron-regulated degradation of the RNA binding protein, iron regulatory protein 2," The EMBO Journal, vol. 14, no. 21, pp. 5350-5357, 1995.

[60] K. Iwai, S. K. Drake, N. B. Wehr et al., "Iron-dependent oxidation, ubiquitination, and degradation of iron regulatory protein 2: implications for degradation of oxidized proteins," Proceedings of the National Academy of Sciences of the United States of America, vol. 95, no. 9, pp. 4924-4928, 1998.

[61] L.-L. Chen and G. G. Carmichael, "Long noncoding RNAs in mammalian cells: what, where, and why?" Wiley Interdisciplinary Reviews: RNA, vol. 1, no. 1, pp. 2-21, 2010.

[62] D. P. Bartel, "MicroRNAs: target recognition and regulatory functions," Cell, vol. 136, no. 2, pp. 215-233, 2009.

[63] M. Faller, M. Matsunaga, S. Yin, J. A. Loo, and F. Guo, "Heme is involved in microRNA processing," Nature Structural \& Molecular Biology, vol. 14, no. 1, pp. 23-29, 2007.

[64] I. Barr, A. T. Smith, Y. Chen, R. Senturia, J. N. Burstyn, and F. Guo, "Ferric, not ferrous, heme activates RNA-binding protein DGCR8 for primary microRNA processing," Proceedings of the National Academy of Sciences of the United States of America, vol. 109, no. 6, pp. 1919-1924, 2012.

[65] L. Zhang, V. G. Sankaran, and H. F. Lodish, "MicroRNAs in erythroid and megakaryocytic differentiation and megakaryocyteerythroid progenitor lineage commitment," Leukemia, vol. 26, no. 11, pp. 2310-2316, 2012.

[66] P. Ponka and J. T. Prchal, "Hereditary and acquired sideroblastic anemias," in Wiiliams Hematology, pp. 865-881, McGraw-Hill, 8th edition, 2010.

[67] H. Harigae and K. Furuyama, "Hereditary sideroblastic anemia: pathophysiology and gene mutations," International Journal of Hematology, vol. 92, no. 3, pp. 425-431, 2010.

[68] K. Yoshida, M. Sanada, Y. Shiraishi et al., "Frequent pathway mutations of splicing machinery in myelodysplasia," Nature, vol. 478 , no. 7367 , pp. 64-69, 2011.
[69] C. Camaschella, "Hereditary sideroblastic anemias: pathophysiology, diagnosis, and treatment," Seminars in Hematology, vol. 46, no. 4, pp. 371-377, 2009.

[70] P. K. Chakraborty, K. Schmitz-Abe, E. K. Kennedy et al., "Mutations in TRNT1 cause congenital sideroblastic anemia with immunodeficiency, fevers, and developmental delay (SIFD)," Blood, vol. 124, no. 18, pp. 2867-2871, 2014.

[71] A. E. Donker, R. A. Raymakers, L. T. Vlasveld et al., "Practice guidelines for the diagnosis and management of microcytic anemias due to genetic disorders of iron metabolism or heme synthesis," Blood, vol. 123, no. 25, pp. 3873-3886, 2014.

[72] B. Grandchamp, G. Hetet, C. Kannengiesser et al., "A novel type of congenital hypochromic anemia associated with a nonsense mutation in the STEAP3/TSAP6 gene," Blood, vol. 118, no. 25, pp. 6660-6666, 2011.

[73] H. Harigae, N. Suwabe, P. H. Weinstock et al., "Deficient heme and globin synthesis in embryonic stem cells lacking the erythroid-specific $\delta$-aminolevulinate synthase gene," Blood, vol. 91, no. 3, pp. 798-805, 1998.

[74] K. Furuyama, H. Harigae, C. Kinoshita et al., "Late-onset Xlinked sideroblastic anemia following hemodialysis," Blood, vol. 101, no. 11, pp. 4623-4624, 2003.

[75] N. Rollón, M. C. Fernández-Jiménez, M. I. Moreno-Carralero, M. J. Murga-Fernández, and M. J. Morán-Jiménez, "Microcytic anemia in a pregnant woman: beyond iron deficiency," International Journal of Hematology, vol. 101, no. 5, pp. 514-519, 2015.

[76] E. Aguiar, M. I. Freitas, and J. Barbot, "Different haematological picture of congenital sideroblastic anaemia in a hemizygote and a heterozygote," British Journal of Haematology, vol. 166, no. 4, p. 469, 2014.

[77] K. Furuyama and S. Sassa, "Multiple mechanisms for hereditary sideroblastic anemia," Cellular and Molecular Biology, vol. 48, no. 1, pp. 5-10, 2002.

[78] A. K. Bergmann, D. R. Campagna, E. M. McLoughlin et al., "Systematic molecular genetic analysis of congenital sideroblastic anemia: evidence for genetic heterogeneity and identification of novel mutations," Pediatric Blood \& Cancer, vol. 54, no. 2, pp. 273-278, 2010.

[79] S. Bekri, A. May, P. D. Cotter et al., "A promoter mutation in the erythroid-specific 5-aminolevulinate synthase (ALAS2) gene causes X-linked sideroblastic anemia," Blood, vol. 102, no. 2, pp. 698-704, 2003.

[80] D. R. Campagna, C. I. de Bie, K. Schmitz-Abe et al., "Xlinked sideroblastic anemia due to ALAS2 intron 1 enhancer element GATA-binding site mutations," American Journal of Hematology, vol. 89, pp. 315-319, 2013.

[81] T. C. Cox, S. S. Bottomley, J. S. Wiley, M. J. Bawden, C. S. Matthews, and B. K. May, "X-linked pyridoxine-responsive sideroblastic anemia due to a THR388-TO-SER substitution in erythroid 5-aminolevulinate synthase," The New England Journal of Medicine, vol. 330, no. 10, pp. 675-679, 1994.

[82] R. Ohba, K. Furuyama, K. Yoshida et al., "Clinical and genetic characteristics of congenital sideroblastic anemia: comparison with myelodysplastic syndrome with ring sideroblast (MDSRS)," Annals of Hematology, vol. 92, no. 1, pp. 1-9, 2013.

[83] M. Ishizuka, F. Abe, Y. Sano et al., "Novel development of 5aminolevurinic acid (ALA) in cancer diagnoses and therapy," International Immunopharmacology, vol. 11, no. 3, pp. 358-365, 2011.

[84] M. Balwani and R. J. Desnick, "The porphyrias: advances in diagnosis and treatment," Hematology, vol. 2012, pp. 19-27, 2012. 
[85] S. A. Holme, M. Worwood, A. V. Anstey, G. H. Elder, and M. N. Badminton, "Erythropoiesis and iron metabolism in dominant erythropoietic protoporphyria," Blood, vol. 110, no. 12, pp. 41084110, 2007.

[86] L. H. P. M. Rademakers, J. C. Koningsberger, C. W. J. Sorber, H. B. de la Faille, J. van Hattum, and J. J. M. Marx, "Accumulation of iron in erythroblasts of patients with erythropoietic protoporphyria," European Journal of Clinical Investigation, vol. 23, no. 2, pp. 130-138, 1993.

[87] A. A. Lamola, S. Piomelli, M. B. P. Fitzpatrick, T. Yamane, and L. C. Harber, "Erythropoietic protoporphyria and lead intoxication: the molecular basis for difference in cutaneous photosensitivity. II. Different binding of erythrocyte protoporphyrin to hemoglobin," The Journal of Clinical Investigation, vol. 56, no. 6, pp. 1528-1535, 1975.

[88] L. Gouya, H. Puy, A.-M. Robreau et al., "The penetrance of dominant erythropoietic protoporphyria is modulated by expression of wildtype FECH," Nature Genetics, vol. 30, no. 1, pp. 27-28, 2002.

[89] L. Gouya, C. Martin-Schmitt, A.-M. Robreau et al., "Contribution of a common single-nucleotide polymorphism to the genetic predisposition for erythropoietic protoporphyria," The American Journal of Human Genetics, vol. 78, no. 1, pp. 2-14, 2006.

[90] E. I. Minder and X. Schneider-Yin, "Afamelanotide (CUV1647) in dermal phototoxicity of erythropoietic protoporphyria," Expert Review of Clinical Pharmacology, vol. 8, no. 1, pp. 43-53, 2015.

[91] D. P. Bentley and E. M. Meek, "Clinical and biochemical improvement following low-dose intravenous iron therapy in a patient with erythropoietic protoporphyria," British Journal of Haematology, vol. 163, no. 2, pp. 289-291, 2013.

[92] S. D. Whatley, S. Ducamp, L. Gouya et al., "C-terminal deletions in the ALAS2 gene lead to gain of function and cause X-linked dominant protoporphyria without anemia or iron overload," The American Journal of Human Genetics, vol. 83, no. 3, pp. 408414, 2008.

[93] S. S. Cooperman, E. G. Meyron-Holtz, H. Olivierre-Wilson, M. C. Ghosh, J. P. McConnell, and T. A. Rouault, "Microcytic anemia, erythropoietic protoporphyria, and neurodegeneration in mice with targeted deletion of iron-regulatory protein 2," Blood, vol. 106, no. 3, pp. 1084-1091, 2005.

[94] M. Balwani, D. Doheny, D. F. Bishop et al., "Loss-offunction ferrochelatase and gain-of-function erythroid-specific 5-aminolevulinate synthase mutations causing erythropoietic protoporphyria and X-linked protoporphyria in North American patients reveal novel mutations and a high prevalence of X-linked protoporphyria," Molecular Medicine, vol. 19, no. 1, pp. 26-35, 2013.

[95] J. To-Figueras, S. Ducamp, J. Clayton et al., "ALAS2 acts as a modifier gene in patients with congenital erythropoietic porphyria," Blood, vol. 118, no. 6, pp. 1443-1451, 2011.

[96] E. Di Pierro, R. Russo, Z. Karakas et al., "Congenital erythropoietic porphyria linked to GATA1-R216W mutation: challenges for diagnosis," European Journal of Haematology, vol. 94, no. 6, pp. 491-497, 2015. 


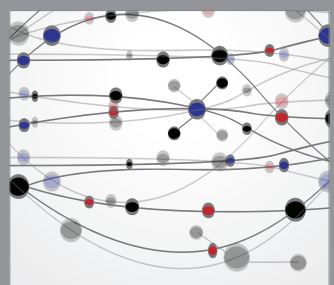

The Scientific World Journal
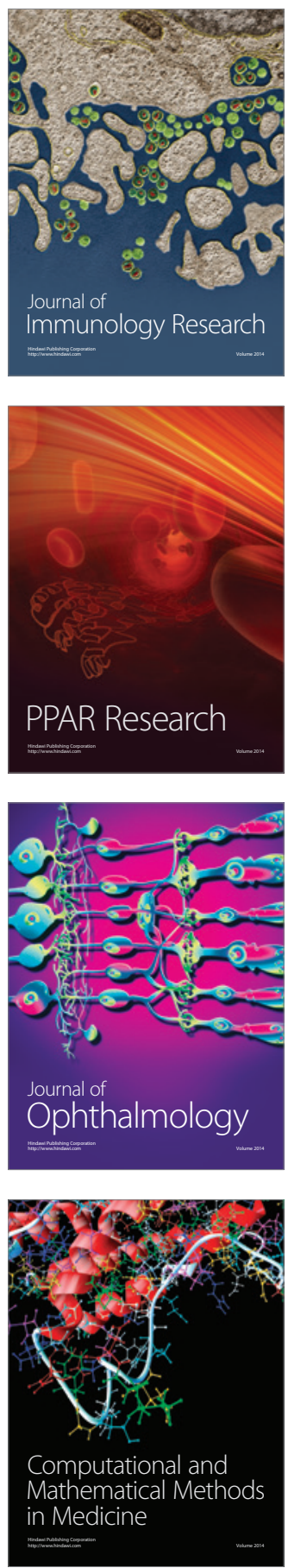

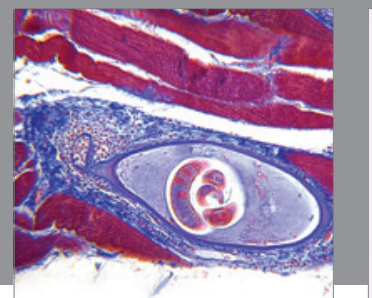

Gastroenterology

Research and Practice
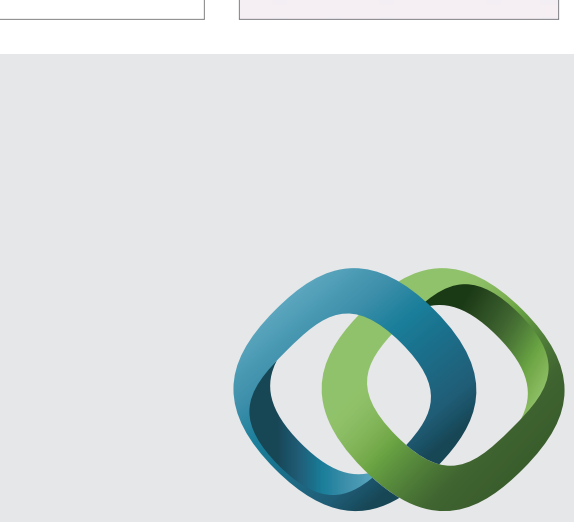

\section{Hindawi}

Submit your manuscripts at

http://www.hindawi.com
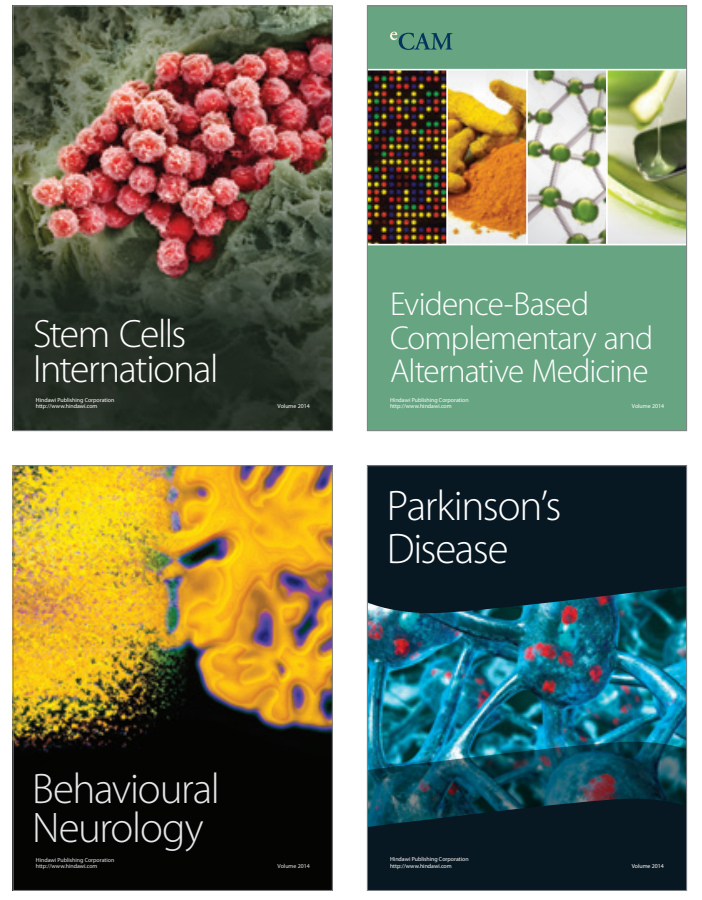
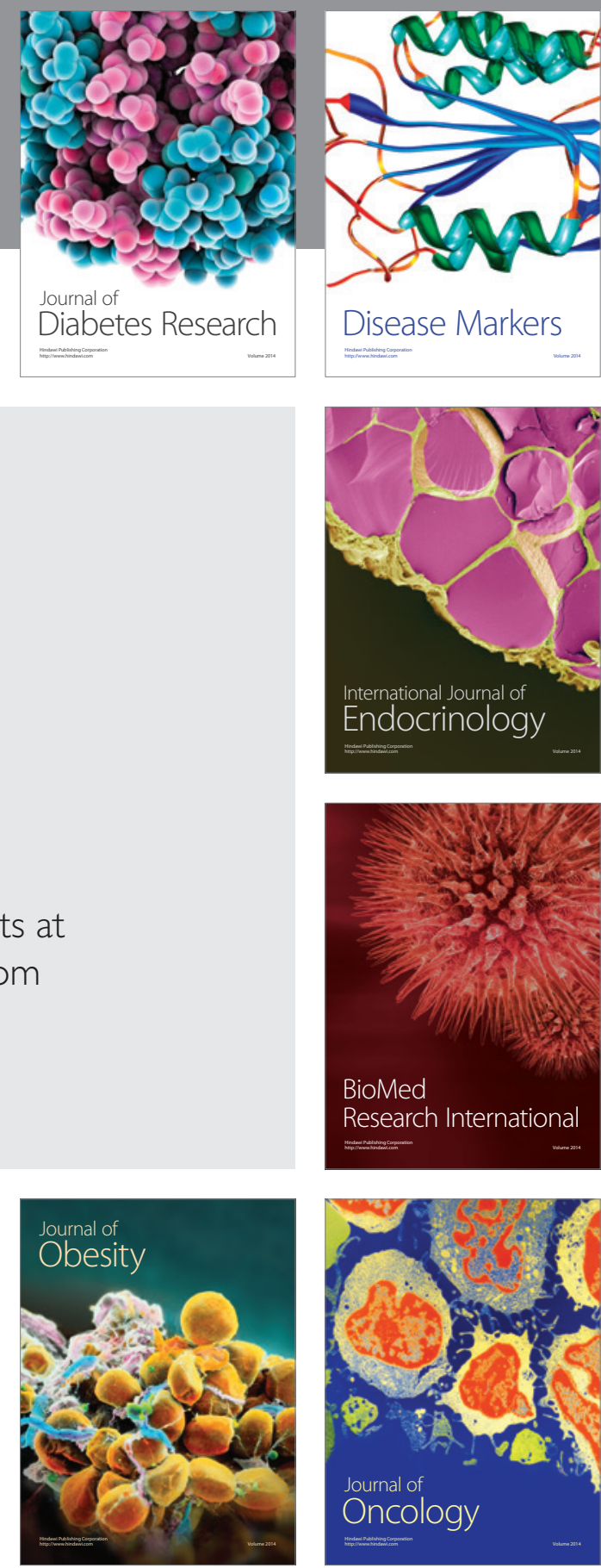

Disease Markers
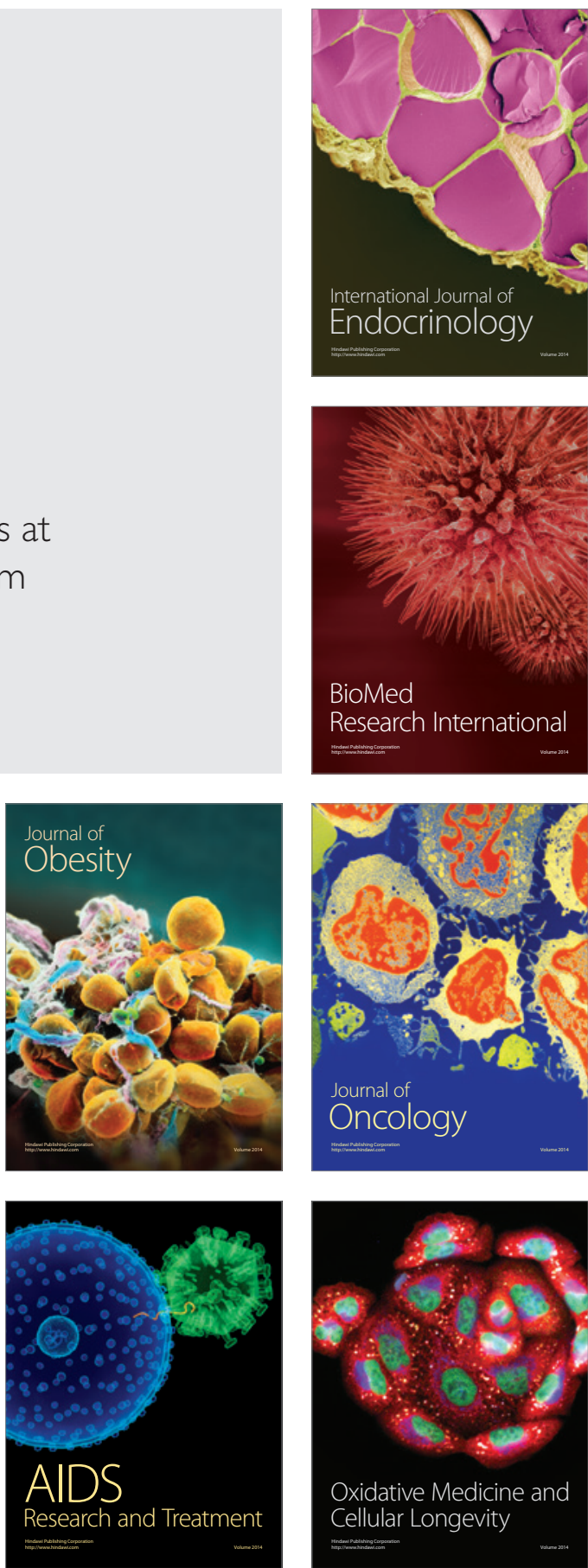